\title{
PSYCHIATRY AND THE ARTS
}

\section{Did the "Father of Aviation" have his wings clipped by depression?}

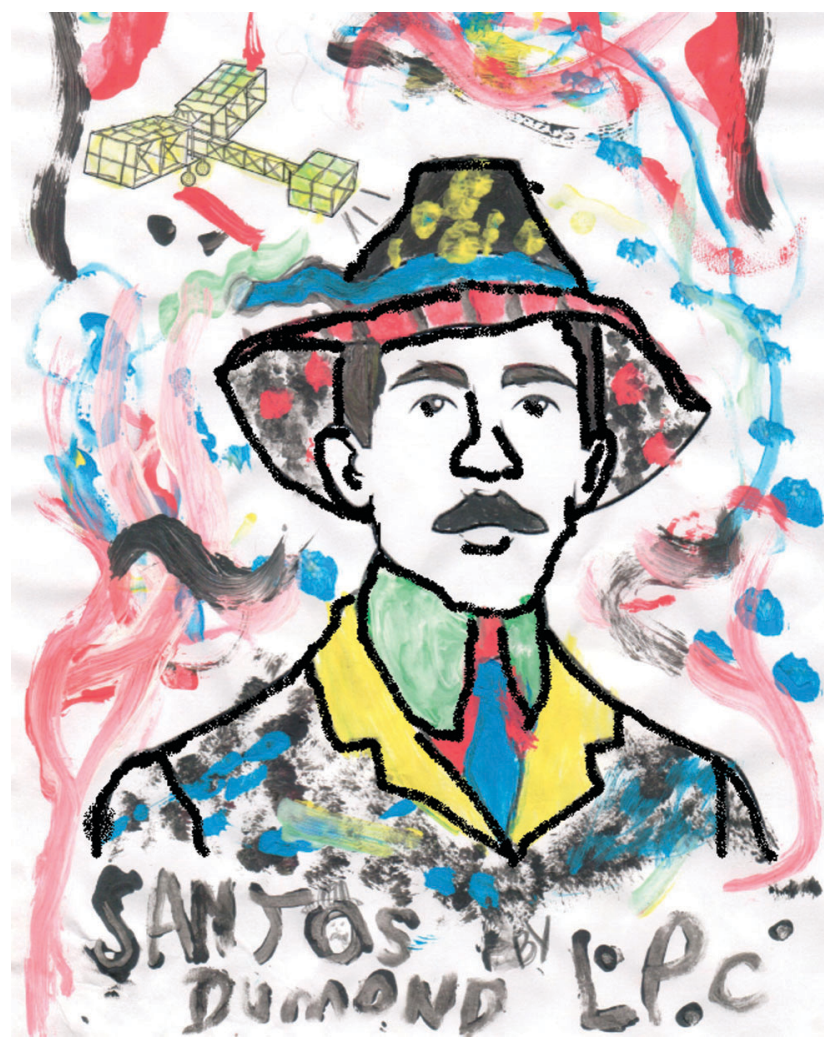

Santos Dumont is one of the greatest Brazilians to rise to international prominence by virtue of his entrepreneurship and creative skills. Aviation owes much to his scientific involvement in the development of aircraft (dirigibles and airplanes). ${ }^{1}$ Although some authors have raised the possibility that Santos Dumont may have had an organic condition of neurologic origin (multiple sclerosis), contemporary accounts do not provide sufficient information to ascertain the accuracy of this hypothesis. However, evidence exists that he experienced a series of depressive symptoms consistent with severe episodes of major depression, some of which may have been compounded by mood-related psychotic symptoms, as Santos Dumont reported a feeling of crippling guilt associated with the use of powered aircraft in warfare during his lifetime. ${ }^{2}$

Treatment of depression in the first half of the 20th century was limited by a lack of pharmacotherapeutic options, many of which are now available; one of the main therapeutic interventions proposed at the time was retirement to health resorts located in lush natural settings. Santos Dumont availed himself of such services for "mental reorganization" while living in Europe and, occasionally, while in Brazil. Unfortunately, his depression did not remit, but gradually worsened, and he eventually committed suicide - by hanging himself with two neckties while staying at a luxury hotel on the coast of São Paulo.

Although sociocultural, genetic, psychodynamic, philosophical, existential, and environmental factors are implicated in suicide, the presence of mental disorder is essentially a given in such cases, with mood disorders being particularly prevalent. The association between depression and suicide in the absence of effective treatment of the former is well established in the literature. ${ }^{3}$ Consequently, even though suicide cannot be entirely predicted, attention to predisposing factors and possible triggers plays an important role in preventing escalation of the risk of suicide and enabling timely implementation of therapeutic measures. ${ }^{4}$ Therefore, access to effective treatment, with proper therapeutic resources and multidisciplinary intervention, is believed to provide the best instrument for suicide prevention. ${ }^{5}$

Over the course of his depressive disorder, and particularly in his last years of life (1928-1932), Santos Dumont exhibited a series of epidemiological risk factors for suicide: male gender, severe depression, advanced age, a comorbid neurologic condition (possibly), feelings of despair and guilt, social isolation, absence of a marital bond, and absence of effective treatment. Therefore, this great Brazilian inventor fits the textbook profile of patients who unfortunately go on to commit suicide. One question begs to be asked during any assessment of this historic event: had Santos Dumont been born after the advent of antidepressants, would he have taken his own life? No answer will ever be available, but this question provides a critical reminder of the need of employing all available means (pharmacological, psychotherapeutic, and social) for the treatment of mental illness and, consequently, the prevention of suicide. Regrettably, few therapeutic resources were available during Santos Dumont's lifetime.

We can only thank this brilliant inventor and scientist whose soaring imagination created devices that continue to make our lives easier. In a tragic turn of events, his own "wings" were "clipped" by the angst of severe depression.

Régis Eric Maia Barros Division of Psychiatry, Department of Neurosciences and Behavioral Sciences, School of Medicine, Universidade de São Paulo, Ribeirão Preto, SP, Brazil

\section{Disclosure}

The author reports no conflicts of interest. 


\section{References}

1 Visoni RM, Canalle JBG. [How Santos Dumont invented the airplane]. Rev Bras Ens Fis. 2009;31:3605.1-6.

2 Musa JL, Mourão MB, Tilkian R. Alberto Santos Dumont: eu naveguei pelo ar. 1st ed. Rio de Janeiro: Nova Fronteira; 2001.

3 Bertolote JM, Fleischmann A, De Leo D, Wasserman D. Suicide and mental disorders: do we know enough? $\mathrm{Br} J$ Psychiatry. 2003;183:382-3.
4 Fleischmann A, Bertolote JM, Wasserman D, De Leo D, Bolhari J, Botega NJ, et al. Effectiveness of brief intervention and contact for suicide attempters: a randomized controlled trial in five countries. Bull World Health Organ. 2008;86:703-9.

5 Daigle MS, Pouliot L, Chagnon F, Greenfield B, Mishara B. Suicide attempts: prevention of repetition. Can J Psychiatry. 2011;56:621-9. 